\title{
Increasing HIV subtype diversity and its clinical implications in a sentinel North American population
}

\author{
Reed AC Siemieniuk MD ${ }^{1,2}$, Brenda Beckthold MSc${ }^{1}$, M John Gill MSc MB ChB ${ }^{1,3}$
}

RAC Siemieniuk, B Beckthold, MJ Gill. Increasing HIV subtype diversity and its clinical implications in a sentinel North American population. Can J Infect Dis Med Microbiol 2013;24(2):69-73.

BACKGROUND: HIV-1 is a highly diverse virus; subtypes may exhibit differences in rates of transmission, disease progression, neurotoxicity, antiretroviral treatment failure profiles and accuracy of viral load measurements. To date, the HIV epidemic in Canada and the rest of the developed world has been largely due to subtype B; however, shifts in subtype epidemiology could have significant implications.

OBJECTIVE: To determine whether there has been an increase in HIV subtype diversity in southern Alberta, Canada.

METHODS: All 2358 patients receiving any HIV care between December 31, 2001 and December 31, 2010 were included in a retrospective analysis of subtype prevalence and incidence. In an indexed analysis, subtype trends from 1994 to 2010 were also evaluated.

RESULTS: Between 2001 and 2010, the prevalence of non-B HIV subtypes in patients with a known subtype increased from $7 \%$ to $24 \%$. In 2010, the most prevalent non-B subtypes were C (65\%), A (11\%), CRFO2_AG (9.7\%), CRF01_AE (4.9\%), D (3.9\%), G (2.9\%) and CRF06_cpx $(1.5 \%)$. In the indexed analysis, there was an overall proportional increase in non-B subtypes of $2.3 \%$ per year. The year-overyear increase in the prevalence of patients infected with a nonsubtype $B$ virus increased from $13 \%$ from 1995 to 2002 to $27 \%$ from 2003 to $2010(\mathrm{P}=0.01)$. Incident non- $\mathrm{B}$ subtype cases increased from $9.6 \%$ to $32.4 \%$ over these time periods.

CONCLUSIONS: This recent and dramatic shift in HIV strain diversity in Canada is unprecedented and may have important public health, research and clinical consequences.

Key Words: AIDS; Clade; Epidemiology; HIV; Strain; Subtype

$\mathrm{M}$ ore than one million people in the United States are infected with HIV-1 and 50,000 are newly infected each year (1); the Public Health Agency of Canada reports that HIV-1 infection affects approximately 65,000 people in Canada, with 2300 to 4300 new infections each year (2). HIV-1 is a highly diverse virus that is classified into four groups: group $\mathrm{M}$ (major), group $\mathrm{O}$ (outlier), group $\mathrm{N}$ (nonmajor nonoutlier) (3) and the new group, P (4). HIV-1 group M, the most prevalent circulating group, has nine subtypes (designated $\mathrm{A}$ to $\mathrm{D}, \mathrm{F}$ to $\mathrm{H}$, and $\mathrm{J}$ and $\mathrm{K}$ ) (5); there is $25 \%$ to $35 \%$ genetic variation among subtypes and up to $20 \%$ variation is observed within a subtype (6). By 2010, more than 50 different circulating recombinant forms (CRFs) of these subtypes have been identified, along with an abundance of unique recombinant forms (URFs) (6). These CRFs and URFs are believed to originate from a recombination of viral genetic material when viruses of two different subtypes infect the same cell. If a recombinant form has been isolated from three independent subjects in separate transmission networks, then, by definition, it is a CRF rather than a URF.

\author{
La diversité croissante de sous-types du VIH et ses \\ répercussions cliniques dans une population \\ sentinelle d'Amérique du Nord
}

HISTORIQUE : Le VIH-1 est un virus très hétérogène, dont les soustypes peuvent différer sur le plan du taux de transmission, de l'évolution de la maladie, de la neurotoxicité, des profils d'échec de traitement antirétroviral et de la précision des mesures de la charge virale. Jusqu'à présent, l'épidémie de VIH au Canada et dans le reste du monde industrialisé est en grande partie attribuable au sous-type B, mais des changements dans l'épidémiologie des sous-types pourraient avoir des conséquences considérables.

OBJECTIF : Déterminer si la diversité des sous-types de VIH a augmenté dans le sud de l'Alberta, au Canada.

MÉTHODOLOGIE : Les 2358 patients qui avaient reçu des soins du VIH entre le 31 décembre 2001 et le 31 décembre 2010 ont participé à une étude rétrospective de la prévalence et de l'incidence des soustypes. Dans une analyse indexée, les tendances de sous-types ont également été évaluées entre 1994 et 2010.

RÉSULTATS : Entre 2001 et 2010, la prévalence des sous-types de VIH non-B chez les patients dont le sous-type est connu est passée de $7 \%$ à $24 \%$. En 2010, les sous-types non-B les plus prévalents étaient les sous-types C (65\%), A (11\%), CRF02_AG (9,7\%), CRF01_AE (4,9\%), D (3,9\%), G (2,9\%) et CRF06_cpx (1,5\%). Dans l'analyse indexée, on constatait une augmentation proportionnelle globale des sous-types non-B de 2,3\% par année. L'augmentation de la prévalence de patients infectés par un virus de sous-type non-B a augmenté d'une année à l'autre, passant de $13 \%$ de 1995 à 2002 à $27 \%$ de 2003 à 2010 $(\mathrm{P}=0,01)$. Les nouveaux cas de sous-types non-B sont passés de $9,6 \%$ à 32,4\% pendant ces périodes.

CONCLUSIONS : Ces changements récents et marqués de la diversité des souches de VIH au Canada sont sans précédent et pourraient avoir des conséquences importantes en matière de santé publique, de recherche et de clinique.

Due to local founder effects, the worldwide spread of HIV resulted in an uneven subtype distribution (6). The HIV epidemic in Canada and in the rest of North America and Europe was likely founded in the 1960s (7) and has been remarkably homogeneous, with HIV-1, group $\mathrm{M}$, subtype B accounting for more than 19 of every 20 infections in these regions (6).

The foundational HIV/AIDS research was mostly undertaken in the developed world and examined largely subtype B infection. Subtype B, however, accounts for only approximately 10\% of HIV infections worldwide. Globally, subtype C accounts for approximately one-half of all infections $(3,6)$. Recent research suggests that the differences in genetic sequences among HIV groups, subtypes and CRFs carry functional biological differences. It has been suggested that these biological differences may have clinically important implications in areas such as transmissibility (8-10), rate of disease progression $(11-16)$, neurotoxicity $(17,18)$, increased susceptibility to antiretroviral resistance due to naturally occurring polymorphisms (19) and

\footnotetext{
${ }^{1}$ Southern Alberta HIV Clinic, Calgary, Alberta; ${ }^{2}$ Department of Medicine, University of Toronto, Toronto, Ontario; ${ }^{3}$ Department of Microbiology, Immunology $\mathcal{E}$ Infectious Diseases, University of Calgary, Calgary, Alberta

Correspondence: Dr M John Gill, Medical Director, Southern Alberta HIV Program, Sheldon M Chumir Health Centre, \#3223, 1213 - 4th

Street Southwest, Calgary, Alberta T2R 0X7. Telephone 403-955-6315, fax 403-955-6333, e-mail john.gill@albertahealthservices.ca
} 
TABLE 1

Study demographics

\begin{tabular}{|c|c|c|c|c|}
\hline & \multicolumn{3}{|c|}{ HIV subtype } & \multirow[b]{2}{*}{ Total $(n=2358)$} \\
\hline & $B(n=854)$ & non-B $(n=268)$ & Unknown (n=1236) & \\
\hline \multicolumn{5}{|l|}{ Sex } \\
\hline Male & $725(84.9)$ & $110(41.0)$ & $971(78.6)$ & $1806(76.6)$ \\
\hline Unknown & $0(0)$ & $0(0)$ & $15(1.2)$ & $15(0.6)$ \\
\hline Age at HIV diagnosis, years, mean \pm SD & $36.5 \pm 9.8$ & $35.5 \pm 10.4$ & $37.5 \pm 9.5$ & $36.8 \pm 9.7$ \\
\hline North America & $743(87.0)$ & $29(10.8)$ & $759(61.4)$ & $1531(64.9)$ \\
\hline Sub-Saharan Africa & $11(1.3)$ & $203(75.7)$ & $152(12.3)$ & $366(15.5)$ \\
\hline Europe & $32(3.7)$ & $3(1.1)$ & $38(3.1)$ & $73(3.1)$ \\
\hline Asia/Middle East & $28(3.3)$ & $17(6.3)$ & $21(2.5)$ & $76(3.2)$ \\
\hline Latin America & $23(2.7)$ & $1(0.4)$ & $21(1.7)$ & $45(1.9)$ \\
\hline Oceania & $5(0.6)$ & $0(0)$ & $2(0.2)$ & $7(0.3)$ \\
\hline Black & $17(2.0)$ & $208(77.6)$ & $158(12.8)$ & $383(16.2)$ \\
\hline Aboriginal* $^{*}$ & $115(13.5)$ & $8(3.0)$ & $135(10.9)$ & $258(10.9)$ \\
\hline Hispanic & $21(2.5)$ & $0(0)$ & $16(1.3)$ & $37(1.6)$ \\
\hline Other & $49(5.7)$ & $21(7.8)$ & $43(3.5)$ & $113(4.8)$ \\
\hline Unknown & $16(1.9)$ & $8(3.0)$ & $248(20.1)$ & $272(11.5)$ \\
\hline \multicolumn{5}{|l|}{ HIV-acquisition risk factor } \\
\hline Heterosexual & $177(20.7)$ & $238(88.8)$ & $305(24.7)$ & $720(30.5)$ \\
\hline Men who have sex with men & $476(55.7)$ & $7(2.6)$ & $451(36.5)$ & $934(39.6)$ \\
\hline Injection drug users & $138(16.2)$ & $3(1.1)$ & $183(14.8)$ & $324(13.7)$ \\
\hline Men who have sex with men and injection drug users & $44(5.2)$ & $0(0)$ & $50(4.0)$ & $94(4.0)$ \\
\hline Other & $9(1.1)$ & $8(3.0)$ & $17(1.4)$ & $34(1.4)$ \\
\hline
\end{tabular}

Data presented as $n$ (\%) unless otherwise indicated. *Includes First Nations, Métis and Inuit

accuracy of commonly used viral load assays $(20,21)$. As such, monitoring the emerging diversity of HIV strains is important for public health programs and individual care (22). Adverse clinical events associated with subtype diversity are increasingly being reported $(21,23,24)$.

Large WHO/Joint United Nations Programme on HIV/AIDS epidemiological studies have reported that the global and regional subtype distributions remain stable (6). However, some cohort studies from parts of South America (25) and Europe, including Spain (26), Italy (27) and Switzerland (28), may have identified early signs of increasing diversity within population subsets. Despite its importance across many domains of HIV research, policy and clinical practice, there has been little evidence of subtype shifts in North America $(6,29)$. Because there is no coordinated subtype monitoring system in North America, geographically defined 'sentinel' centres offer the most sensitive and accurate way to detect changes in subtype epidemiology $(30,31)$. We report trends in HIV diversity in a large, geographically defined Canadian population of HIV-infected patients.

\section{METHODS}

The Southern Alberta HIV Program provides exclusive care to HIVinfected patients living in southern Alberta, a region of approximately 1.7 million people. All patients receiving any care between December 31, 2001, and December 31, 2010 were included in the evaluation of known HIV subtypes. Medical records from the clinic database were used to gather data; administrative data use was reviewed and approved by the Conjoint Health Research Ethics Board, University of Calgary, Calgary, Alberta.

HIV typing was derived from the pol gene sequence during routine genotypic resistance testing. When available, whole genome sequence typing was used for further clarification. Resistance testing was introduced in
2001 exclusively for patients failing antiretroviral therapy (ART) and formally expanded in 2006 to include all patients initiating ART. When a subtype was only determined after years in care, this subtype was used retrospectively for that individual.

Because subtype analysis can only be easily undertaken when the plasma RNA viral load is $>250$ copies $/ \mathrm{mL}$, patients who moved to the study region while on ART and with an undetectable viral load or have consistently had $<250$ viral copies/mL since 2001 do not have a subtype classification. To address these missing subtype data, country of birth was used (currently a very strong demographic marker of HIV subtype in this population) to predict subtype B or nonsubtype B infection. As previously established, $97 \%$ of Canadian and $5 \%$ of subSaharan African-born patients were HIV subtype B (32). These subtype proportions were applied to the remaining patients born in sub-Saharan Africa and Canada without a known subtype. This enabled a more accurate prediction of population-level data; however, individual-level demographic data could not be studied for patients with an unknown subtype. Due to uncertainty in subtype prediction for individuals born in other geographical areas, these patients were classified as unknown subtype. To ensure that there was no selection bias with clinical subtype testing, the proportions of African-born and Canadian-born patients with HIV subtype testing were compared at the beginning and at the end of the study (2001 and 2010).

Subtype incidence is defined as the sum of patients newly diagnosed with HIV and patients with a known HIV diagnosis but new to southern Alberta, each calendar year. Prevalence is the point-prevalence, defined as the total number of patients in the region on December 31; for simplicity, only the year is mentioned hereafter.

To evaluate whether there were any changes in the year-over-year incidence of B and non-B HIV subtypes, proportional and absolute year-over-year changes in incidence during the first one-half of the 


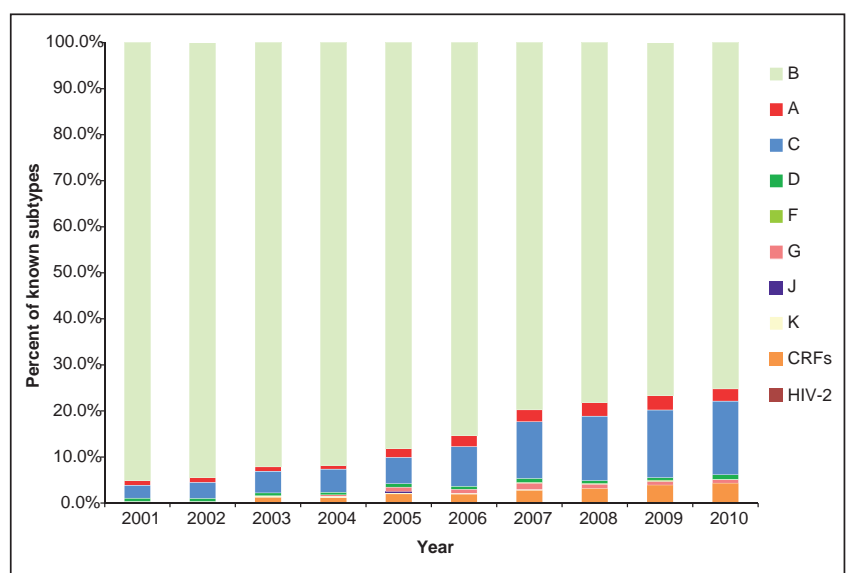

Figure 1) Prevalence of known HIV-1 subtypes in southern Alberta, 2001 to 2010. CRF Circulating recombinant form

study period (1995 to 2002) were compared with the second one-half (2003 to 2010).

Pearson's $\chi^{2}$ and Student's $t$ tests were used as appropriate with statistical significance set at $\mathrm{P}<0.05$. All statistical analyses were performed using SPSS version 20 (IBM Corporation, USA).

\section{RESULTS}

There were 2358 patients engaged in HIV care between December 31, 2001 and December 31, 2010 (Table 1). In patients with a known subtype, there was no age difference between patients with subtype $B$ and non- $B(P=0.15)$. Male patients were more likely to be infected with subtype $B(P<0.001)$. Patients born in North America were more likely than patients born in sub-Saharan Africa to be infected with subtype $B$ $(\mathrm{P}<0.001)$. Men who have sex with men were more likely than heterosexual men and women to be infected with subtype $B(P<0.001)$.

The number of HIV-infected patients with a known HIV subtype increased from 284 of 683 active patients (42\%) in 2001 to 831 of 1336 patients $(62 \%)$ in 2010 . Of the patients with a known viral subtype, in 2001, 95.1\% of patients were infected with subtype B but 14 of these 284 patients were infected with a non-B subtype. By contrast, in 2010, the prevalence of all non-B infections increased to 206 of 831 patients $(24.7 \% ; \mathrm{P}<0.0001)$ (Figure 1$)$.

In 2010, $66 \%$ of patients were born in Canada and $19 \%$ in subSaharan Africa. There was no difference in subtype testing rates between Canadian-born and sub-Saharan African-born patients in either 2001 or 2010. In 2001, 45.5\% (15 of 33) of sub-Saharan African-born patients were subtyped and $43.5 \%$ (249 of 573) of Canadian-born patients were subtyped $(\mathrm{P}=0.86)$; in 2010, subtyping rates increased to $64.1 \%$ (166 of 259 ) and $63.6 \%$ (560 of 881 ), respectively $(\mathrm{P}=0.94)$. Using a conservative index according to region of birth for patients without a known subtype (using only data from patients born in Canada and sub-Saharan Africa) in addition to patients with a known subtype, it was estimated that in 2010, at least 305 of 1257 patients $(24.3 \%)$ were infected with a non-B subtype, confirming a dramatic increase from 2001, when 43 of 632 patients $(6.8 \%)$ were infected with a non-B subtype $(\mathrm{P}<0.0001)$.

Significant diversity was identified in the patient population, with one HIV-2 infection, eight different HIV-1 subtypes and six different CRFs. In 2010, the predominant nonsubtype B viruses identified were subtypes C (65\%), A (11\%), CRF02_AG (9.7\%), CRF01_AE (4.9\%), D (3.9\%), G (2.9\%) and CRF06_cpx (1.5\%) (Figure 2).

The increasing viral diversity in new HIV patients (incidence) with a known subtype over this time period has driven this change. In $2001,84 \%$ of incident cases with a known viral subtype were infected with subtype B; however, by 2010 , only $67 \%$ of 132 new patients with known subtype were infected with subtype B (Figure 3).

The evolving diversity data were modelled in an attempt to predict future trends (Figure 4). A linear fitted curve showed a $2.3 \%$ per-year

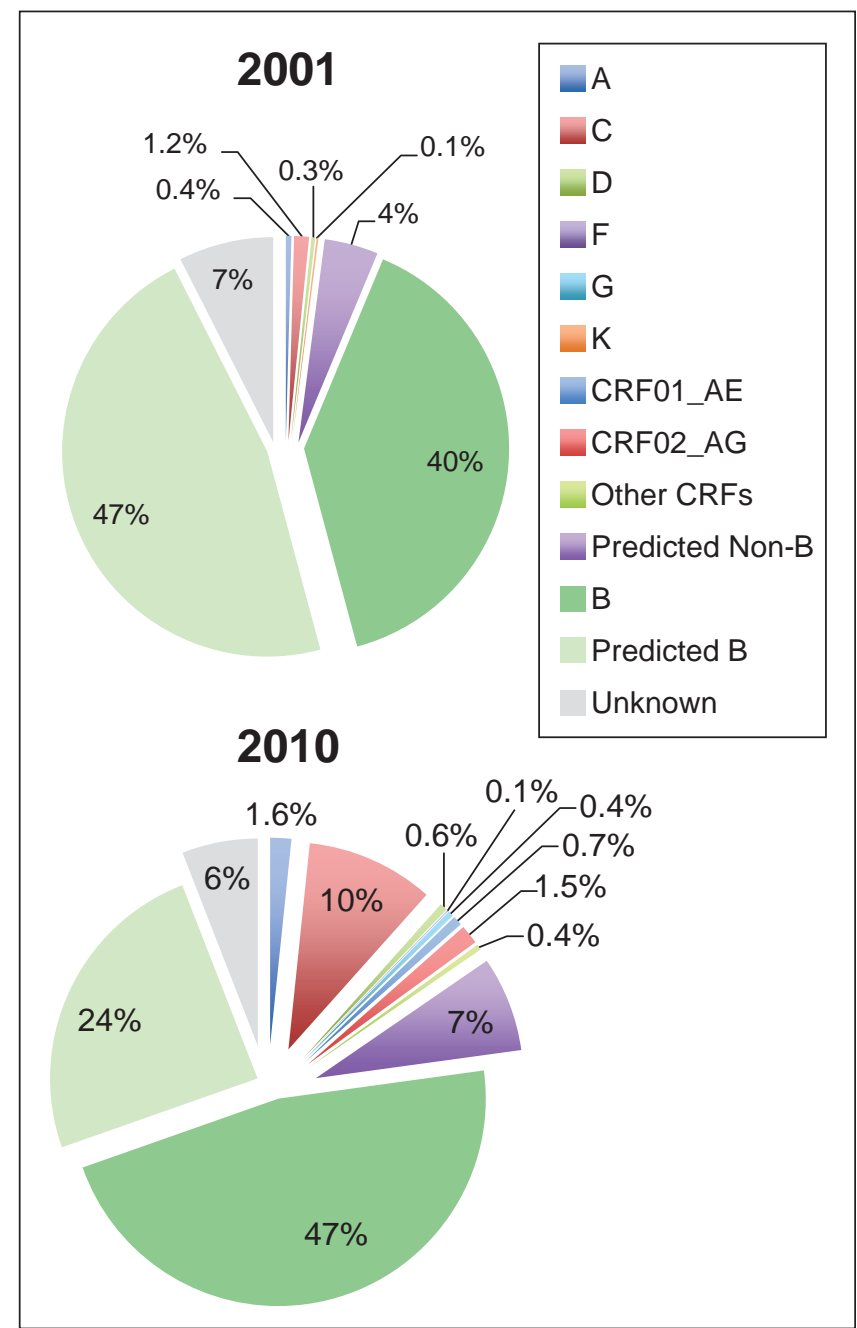

Figure 2) Prevalence of known HIV-1 and predicted subtypes in Southern Alberta on December 31, 2001 and December 31, 2010. CRF Circulating recombinant form

increase in the proportion of new patients presenting with non- $B$ versus $B$ viruses $\left(R^{2}=0.80\right)$ over the past 17 years. There was an average proportional yearly increase in the incidence of non- $B$ viruses from $0.1 \%$ per year from 1995 to 2002 and 3.2\% from 2003 to 2010. Of new patients with a predicted subtype, $9.6 \%$ and $32.4 \%$ were non-B over these same periods, respectively $(\mathrm{P}<0.001)$. The year-over-year increase in absolute number of patients infected with a non-B virus was $13 \%$ from 1995 to 2002 and increased to $27 \%$ from 2003 to 2010 $(\mathrm{P}=0.01)$. In contrast, the average year-over-year increase in prevalence in patients infected with a B virus was stable $(6.1 \%)$ for these same periods, respectively $(\mathrm{P}=0.98)$. This represents a sevenfold increase in non-B subtype infections over the past decade.

\section{DISCUSSION}

Our results document acceleration in HIV subtype diversity in a sentinel Canadian population over the past decade and suggest that the prevalence of non-B subtypes will continue to increase disproportionately to B subtypes. Travel and acquisition of infection abroad, immigration policy, as well as domestic transmission of non-B subtypes may contribute to viral diversity in developed countries $(22,28,32)$. Immigrants from endemic countries are more likely to be infected with non-B subtypes and comprise approximately $17 \%$ and $35 \%$ of new HIV diagnoses in Canada (1) and Europe (33), respectively. Although immigration patterns may explain much of the increasing diversity, it is an incomplete explanation because there is mounting evidence of increasing non-B transmission within Canada as well (32). 


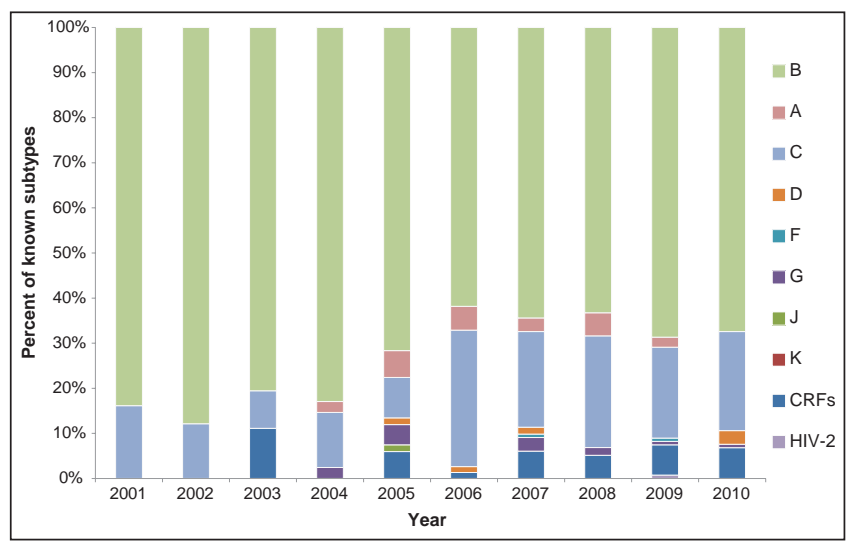

Figure 3) Incident HIV-1 cases to the Southern Alberta HIV Program, 2001 to 2010, according to subtype. CRF Circulating recombinant forms

Among the patients with non-B infection, the predominance of subtype $\mathrm{C}$, followed by subtype $\mathrm{A}$, is similar to the prevalence seen globally (6). Importantly, this trend may be the first signal that subtype B will soon no longer be the dominant HIV-1 subtype in Canada and many other developed countries. This trend has been reported in some European HIV cohorts (26-28) but, until now, has not been apparent in North America. Similar to other populations, there was also an increase in the number of CRFs over the course of the study period, reflecting an increasing complexity of HIV genetics (6). The number and prevalence of recombinants will likely continue to increase given the additive opportunities for genetic recombination.

While increasing diversity is of epidemiological interest, there are far-reaching clinical implications. Adverse clinical outcomes due to inaccurate HIV viral load quantification of non-B subtypes have been reported by our group (23) and by others $(21,24)$. Identifying and addressing the challenges of HIV diversity is particularly important in the field of molecular laboratory medicine. Several recent studies have shown that primers designed for quantifying HIV-1 subtype B in viral load assays may be unreliable quantifying some non-B subtypes $(20,21)$. Our results suggest that the local epidemiology of viral subtypes should be a deciding factor in selecting the most appropriate quantitative viral load assay.

There is some evidence to suggest that HIV subtype may affect disease transmission, progression and response to therapy. For example, subtype C may be more easily transmitted from mother to child (8) and may exhibit higher viral shedding in the vagina than subtypes $\mathrm{A}$ or D (9). There may also be differences in rates of heterosexual transmission (10). These results remain intriguing, but the role of confounders needs to be addressed. Subtype D may progress more rapidly (13-16), while subtype A may have a slower disease progression $(12,13)$. Further in vivo and in vitro evidence also suggests differences in progression rates between subtypes (11); however, the full clinical implications for each subtype are not yet understood (3).

One group suggested that subtypes may vary in neuropathogenicity based on studies with animal models (17). Early observational studies have supported this suggestion by reporting a difference in rates of dementia between subtypes (18). The role of subtypes in other areas of disease severity is as yet poorly understood.

Low-frequency natural polymorphisms associated with drug resistance to nucleotide and non-nucleotide reverse-transcriptase inhibitors (NRTI and NNRTI) have been widely described in subtype C, but not subtype B (34). This raises the concern that some NRTI/NNRTI combinations are more likely to fail than other regimens in subtype $\mathrm{C}$ infection due to selection of these mutations conferring resistance (35). The implications for NRTI-based pre- and postexposure prophylaxis of low frequency polymorphisms, such as the K65R in subtype C, which are associated with drug resistance and are more common in

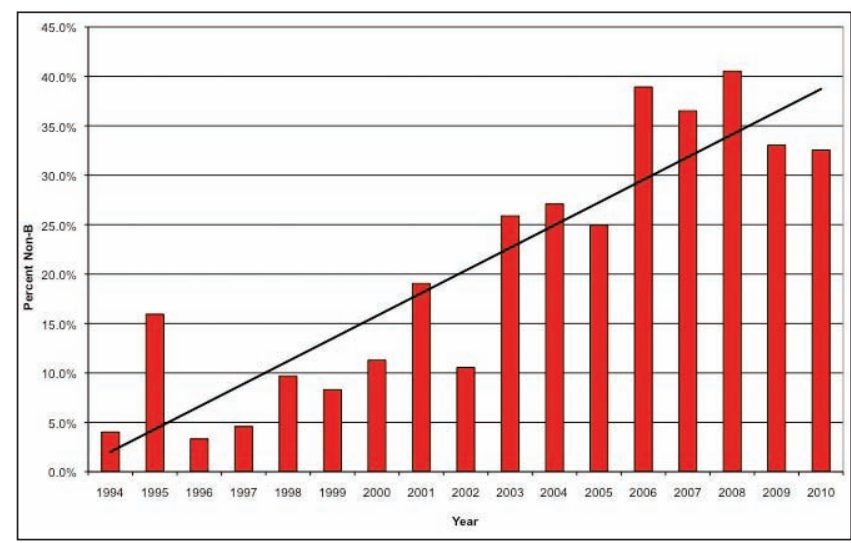

Figure 4) Proportion of new patients with non-B subtypes indexed according to year, 1994 to 2010

certain subtypes, warrant further study. Polymorphisms leading to decreased susceptibility to protease inhibitors (36) and integrase inhibitors (37) have also been identified in certain non-B subtypes. Subtype differences in HIV coreceptor tropism have been reported, with potential implications for disease progression and therapy with entry inhibitors (38).

All of these observations raise the concern that certain subtypes may be more likely to fail therapy in the common scenario of good but suboptimal drug adherence, ultimately leading to poor outcomes (19). Clinical cohort studies have not yet been adequately powered to address failure rates of individual subtype-regimen combinations. While subtle differences have been suggested in population-based studies investigating rates of viral load suppression, they have not had sufficently long follow-up or enough statistical power for definitive results $(3,39)$. A recent study $(40)$ implied superior response to therapy among subtypes A and CRFO2_AG compared with subtype B. The role of subtype-tailored combination therapy in minimizing the risk of future failure remains uncertain at present.

There are some limitations to the present study. Being retrospective in nature, the study did not have complete subtype classification on all patients in care over the study period. To address any bias of using a clinical database retrospectively, we indexed unknown subtypes based on region of birth, which was such a specific marker that indexing to birth region on a population level likely had higher accuracy than predicting subtypes for individual patients. Furthermore, we have also assumed that if any, the number of super infections 'changing' a viral subtype over time was insignificant. Subtypes were based on the pol region in most patients and, thus, it is possible that the true prevalence of CRFs may be underestimated. The study was limited to southern Alberta and may not completely reflect the size or diversity of subtypes elsewhere due to differing immigration and migratory travel patterns. Many factors, such as federal government immigration policies and other social and geopolitical factors, may impact future HIV subtype trends beyond the scope of the present analysis. However, there is no reason to believe that these trends are unique to this geographical region of Canada and, if anything, the trend may be more dramatic in large urban centres with higher immigration rates and HIV prevalence.

\section{CONCLUSION}

Over the past 10 years, there has been a dramatic increase in viral diversity in a large, geographically defined cohort of HIV-infected patients in Canada - the prevalence of non-B subtype infections rose from $6.8 \%$ to $24 \%$ over the past decade. Furthermore, this trend is accelerating, with a dramatic $27 \%$ yearly increase in prevalence of non- $\mathrm{B}$ viruses over the past eight years. To our knowledge, we are the first to report such a major change in HIV viral diversity within North 
America. Many studies are now reporting clinically important differences among subtypes, which necessitates ongoing surveillance and adaptation of clinical algorithms as the need arises. This shift in HIV diversity is poorly reported in developed countries, will inevitably continue, and will pose new challenges to HIV programs in Canada and other developed nations.

\section{REFERENCES}

1. Moore RD. Epidemiology of HIV infection in the United States: Implications for linkage to care. Clin Infect Dis 2011;52:S208-13.

2. Public Health Agency of Canada. HIV/AIDS Epi Updates: National HIV prevalence and incidence estimates in Canada for 2008. Ottawa: Public Health Agency of Canada, 2010.

3. Taylor BS, Sobieszczyk ME, McCutchan FE, Hammer SM. The challenge of HIV-1 subtype diversity. N Engl J Med 2008;358:1590-602.

4. Plantier JC, Leoz M, Dickerson JE, et al. A new human immunodeficiency virus derived from gorillas. Nat Med 2009; 15:871-2.

5. Robertson DL, Anderson JP, Bradac JA, et al. HIV-1 nomenclature proposal. Science 2000;288:55-6.

6. Hemelaar J, Gouws E, Ghys PD, Osmanov S; WHO-UNAIDS Network for HIV Isolation and Characterisation. Global trends in molecular epidemiology of HIV-1 during 2000-2007. AIDS 2011;25:679-89.

7. Gilbert MT, Rambaut A, Wlasiuk G, Spira TJ, Pitchenik AE, Worobey M. The emergence of HIV/AIDS in the Americas and beyond. Proc Natl Acad Sci USA 2007;104:18566-70.

8. Renjifo B, Gilbert P, Chaplin B, et al. Preferential in-utero transmission of HIV-1 subtype C as compared to HIV-1 subtype A or D. AIDS 2004;18:1629-36.

9. John-Stewart GC, Nduati RW, Rousseau CM, et al. Subtype C is associated with increased vaginal shedding of HIV-1. J Infect Dis 2005;192:492-6.

10. Kiwanuka N, Laeyendecker O, Quinn TC, et al. HIV-1 subtypes and differences in heterosexual HIV transmission among HIVdiscordant couples in Rakai, Uganda. AIDS 2009;23:2479-484.

11. Keller M, Lu Y, Lalonde RG, Klein MB. Impact of HIV-1 viral subtype on CD4+ T-cell decline and clinical outcomes in antiretroviral naive patients receiving universal healthcare. AIDS 2009;23:731-7.

12. Kanki PJ, Hamel DJ, Sankale JL, et al. Human immunodeficiency virus type 1 subtypes differ in disease progression. J Infect Dis 1999;179:68-73.

13. Kiwanuka N, Laeyendecker O, Robb M, et al. Effect of human immunodeficiency virus type 1 (HIV-1) subtype on disease progression in persons from Rakai, Uganda, with incident HIV-1 infection. J Infect Dis 2008;197:707-13.

14. Baeten JM, Chohan B, Lavreys L, et al. HIV-1 subtype D infection is associated with faster disease progression than subtype $\mathrm{A}$ in spite of similar plasma HIV-1 loads. J Infect Dis 2007;195:1177-80.

15. Vasan A, Renjifo B, Hertzmark E, et al. Different rates of disease progression of HIV type 1 infection in Tanzania based on infecting subtype. Clin Infect Dis 2006;42:843-52.

16. Kiwanuka N, Robb M, Laeyendecker O, et al. HIV-1 viral subtype differences in the rate of CD4+ T-cell decline among HIV seroincident antiretroviral naive persons in Rakai district, Uganda. J Acquir Immune Defic Syndr 2010;54:180-4.

17. Rao VR, Sas AR, Eugenin EA, et al. HIV-1 clade-specific differences in the induction of neuropathogenesis. J Neurosci 2008;28:10010-6.

18. Sacktor N, Nakasujja N, Skolasky RL, et al. HIV subtype D is associated with dementia, compared with subtype $\mathrm{A}$, in immunosuppressed individuals at risk of cognitive impairment in Kampala, Uganda. Clin Infect Dis 2009;49:780-6.

19. Martinez-Cajas JL, Pai NP, Klein MB, Wainberg MA. Differences in resistance mutations among HIV-1 non-subtype B infections: A systematic review of evidence (1996-2008). J Int AIDS Soc 2009;12:11.
20. Church D, Gregson D, Lloyd T, et al. Comparison of the RealTime HIV-1, COBAS TaqMan 48 v1.0, Easy Q v1.2, and Versant v3.0 assays for determination of HIV-1 viral loads in a cohort of Canadian patients with diverse HIV subtype infections. J Clin Microbiol 2011;49:118-24.

21. Bolivar H, Geffin R, Manzi G, et al. The challenge of HIV-1 genetic diversity: Discordant CD4+ T-Cell count and viral load in an untreated patient infected with a subtype $F$ strain. J Acquir Immune Defic Syndr 2009;52:659-61.

22. Krentz H, Gill MJ. The five-year impact of an evolving global epidemic, changing migration patterns, and policy changes in a regional Canadian HIV population. Health Policy 2009;90:296-302.

23. O'Bryan T, Jadavji T, Kim J, Gill MJ. An avoidable transmission of HIV from mother to child. CMAJ 2011;183:690-2.

24. Delaugerre C, Denis B, Peytavin G, et al. Clinical and resistance consequences of misquantification of plasma and cerebrospinal fluid human immunodeficiency virus type 1 (HIV-1) RNA in samples from an HIV-1 subtype G-infected patient. J Clin Microbiol 2009;47:3763-4.

25. Locateli D, Stoco PH, de Queiroz AT, et al. Molecular epidemiology of HIV-1 in Santa Catarina State confirms increases of subtype C in Southern Brazil. J Med Virol 2007;79:1455-63.

26. Holguín A, de Mulder M, Yebra G, López M, Soriano V. Increase of non-B subtypes and recombinants among newly diagnosed HIV-1 native Spaniards and immigrants in Spain. Curr HIV Res 2008;6:327-34.

27. Lai A, Riva C, Marconi A, et al. Changing patterns in HIV-1 non-B clade prevalence and diversity in Italy over three decades. HIV Med 2010;11:593-602.

28. von Wyl V, Kouyos RD, Yerly S, et al; Swiss HIV Cohort Study. The role of migration and domestic transmission in the spread of HIV-1 non-B subtypes in Switzerland. J Infect Dis 2011;204:1095-103.

29. Wheeler WH, Ziebell RA, Zabina H, et al; Resistant HIV Surveillance Group. Prevalence of transmitted drug resistance associated mutations and HIV-1 subtypes in new HIV-1 diagnoses, U.S.-2006. AIDS 2010;24:1203-12.

30. Bennett D. HIV (corrected) genetic diversity surveillance in the United States. J Infect Dis 2005;192:4-9.

31. Salemi M. Toward a robust monitoring of HIV subtypes distribution worldwide. AIDS 2011;25:713-4.

32. Luft LM, Beckthold B, Gill MJ. Increasing HIV subtype diversity in Canadian born patients living in southern Alberta, Canada. J Acquir Immune Defic Syndr 2011;57:e27-9.

33. Del Amo J, Likatavicius G, Pérez-Cachafeiro S, et al. The epidemiology of HIV and AIDS reports in migrants in the 27 European Union countries, Norway and Iceland: 1999-2006. Eur J Public Health 2011;21:620-6.

34. Invernizzi CF, Coutsinos D, Oliveira M, Moisi D, Brenner BG, Wainberg MA. Signature nucleotide polymorphisms at positions 65 in RT favour selection of K65 R mutation in HIV 1 Subtype C. J Infect Dis 2009;200:1202-6.

35. Brenner BG, Oliveira M, Doualla-Bell F, et al. HIV-1 subtype C viruses rapidly develop $\mathrm{K} 65 \mathrm{R}$ resistance to tenofovir in cell culture. AIDS 2006;20:F9-13.

36. Kinomoto M, Appiah-Opong R, Brandful JA, et al. HIV proteases from drug naïve West Africans are differentially susceptible to protease inhibitors. Clin Infect Dis 2005;41:243-51.

37. Brenner BG, Lowe M, Moisi D, et al. Subtype diversity associated with the development of HIV-1 resistance to integrase inhibitors. J Med Virol 2011;83:751-9.

38. Huang W, Eshleman SH, Toma J, et al. Coreceptor tropism in human immunodeficiency virus type 1 subtype D: High prevalence of CXCR4 tropism and heterogeneous composition of viral populations. J Virol 2007;81:7885-93.

39. Geretti AM, Harrison L, Green H, et al; UK Collaborative Group on HIV Drug Resistance. Effect of HIV-1 subtype on virologic and immunologic response to starting highly active antiretroviral therapy. Clin Infect Dis 2009;48:1296-305.

40. Scherrer AU, Ledergerber B, von Wyl V, et al; Swiss HIV Cohort Study. Improved virological outcome in white patients infected with HIV-1 non-B subtypes compared to subtype B. Clin Infect Dis 2011;53:1143-52. 


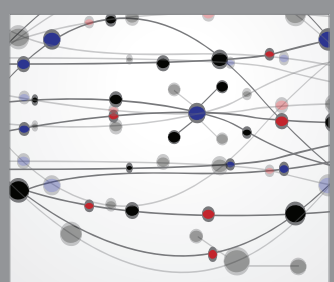

The Scientific World Journal
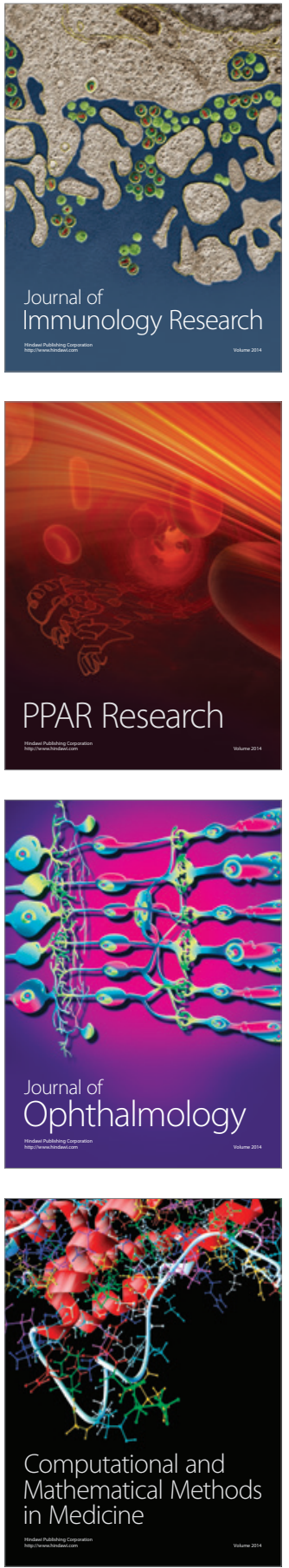

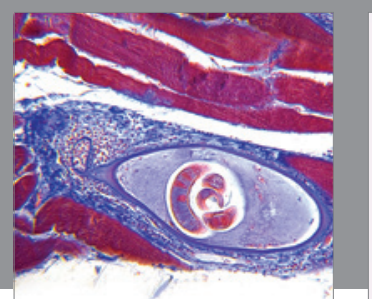

Gastroenterology Research and Practice

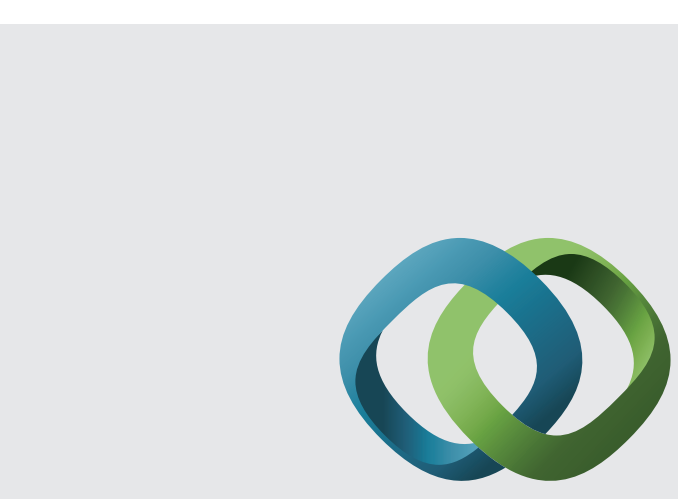

\section{Hindawi}

Submit your manuscripts at

http://www.hindawi.com
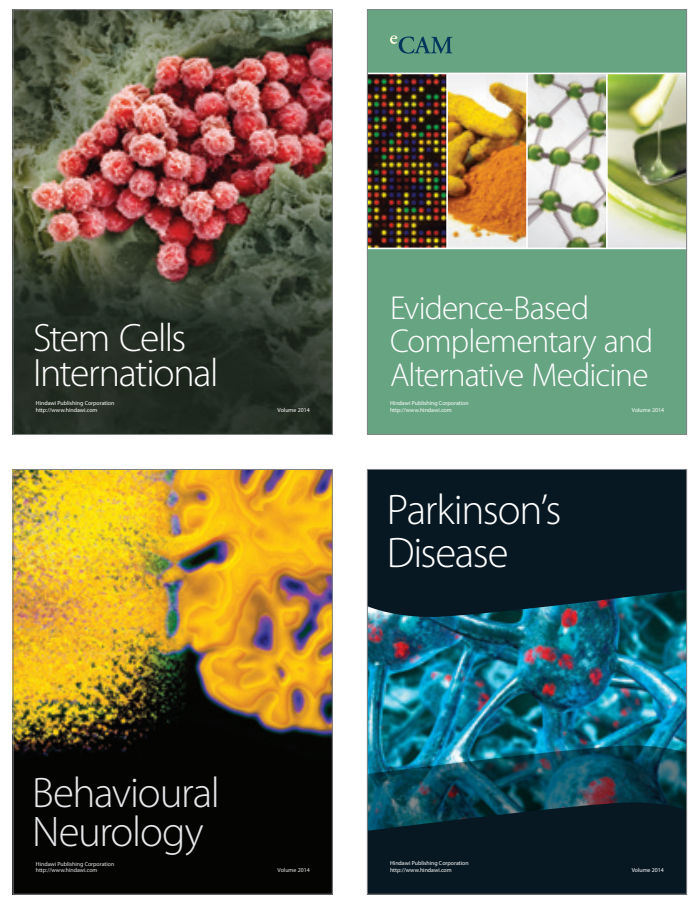
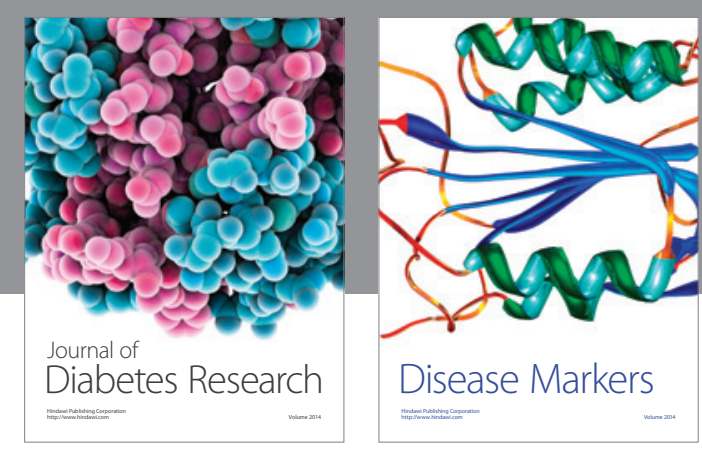

Disease Markers
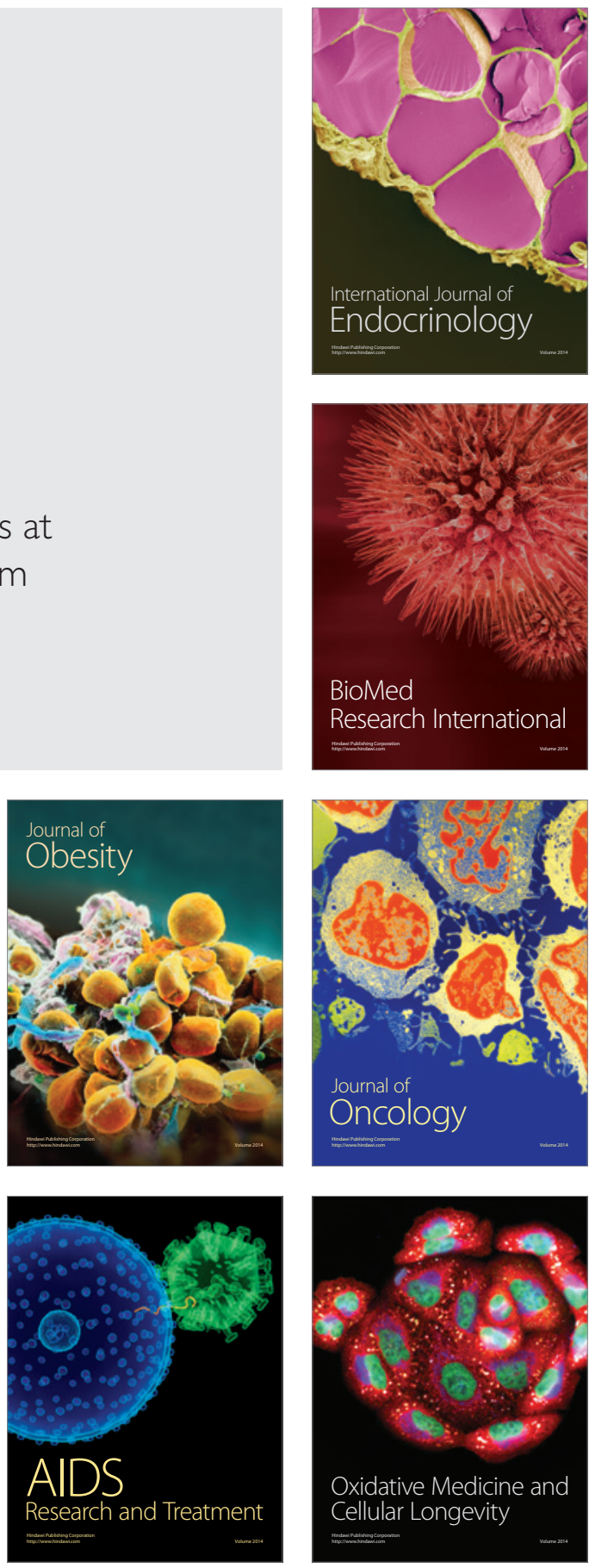